\title{
Lower serum chloride concentrations are associated with increased risk of mortality in critically ill cirrhotic patients: an analysis of the MIMIC-III database
}

\author{
Yun Ji and Libin Li
}

\begin{abstract}
Background: Cirrhosis can be complicated by electrolyte abnormalities, but the major focus has been concentrated on the clinical significance of serum sodium levels. Emerging studies have identified hypochloremia as an independent prognostic marker in patients with chronic heart failure and chronic kidney disease. The aim of this study was to investigate whether serum chloride levels were associated with mortality of critically ill cirrhotic patients.
\end{abstract}

Methods: Critically ill cirrhotic patients were identified from the Multi-parameter Intelligent Monitoring in Intensive Care III Database. The primary outcome was ICU mortality. Logistic regression was used to explore the association between serum chloride levels and ICU mortality. The area under the receiver operating characteristic curves (AUC) was used to assess the performance of serum chloride levels for predicting ICU mortality.

Results: A total of 1216 critically ill cirrhotic patients were enrolled in this study. The overall ICU mortality rate was 18.8\%. Patients with hypochloremia had a higher ICU mortality than those with non-hypochloremia (34.2\% vs. 15.8\%; $p<0.001)$. After multivariable risk adjustment for age, gender, ethnicity, chloride, sodium, Model for End-stage Liver Disease score, Sequential Organ Failure Assessment score, Elixhauser comorbidity index, mechanical ventilation, vasopressors, renal replacement therapy, acute kidney injury, hemoglobin, platelet, and white blood cell, serum chloride levels remained independently associated with ICU mortality (OR 0.94; $95 \% \mathrm{Cl} 0.91-0.98 ; p=0.002)$ in contrast to serum sodium levels, which were no longer significant (OR 1.03; 95\% Cl 0.99-1.08; $p=0.119$ ). The AUC of serum chloride levels (AUC, $0.600 ; 95 \% \mathrm{Cl} 0.556-0.643$ ) for ICU mortality was statistically higher than that of serum sodium levels (AUC, 0.544; 95\% Cl 0.499-0.590) ( $p<0.001)$.

Conclusions: In critically ill cirrhotic patients, serum chloride levels are independently and inversely associated with ICU mortality, thus highlighting the prognostic role of serum chloride levels which are largely overlooked.

Keywords: Hypochloremia, Liver cirrhosis, Mortality, Critical illness

*Correspondence: yunji@zju.edu.cn

Department of Surgical Intensive Care Unit, The Second Affiliated Hospital, School of Medicine, Zhejiang University, 88 Jiefang Road, Hangzhou 310009, Zhejiang, China

\section{Background}

Abnormalities in serum electrolyte levels often complicate cirrhosis [1]. Serum sodium has long been considered as an important electrolyte prognostic marker [2,3]. It has been suggested that the addition of serum sodium to the Model for End-stage Liver Disease (MELD) score would increase its accuracy in predicting mortality [4]. 
However, the prognostic value of serum chloride and its interplay with serum sodium in patients with cirrhosis is less well understood despite its broad availability in routinely used blood chemistry panels.

Chloride as the principal extracellular anion accounts for approximately one-third of plasma tonicity and twothirds of negative charges [5]. Serum chloride performs a large number of functions in the body including the maintenance of osmotic pressure, acid-base balance, muscular activity, and the regulation of body fluid distribution [6]. Emerging studies have identified hypochloremia as an independent prognostic marker in patients with chronic heart failure and chronic kidney disease [7-12]. However, serum chloride has scarcely been investigated as a potential biomarker of cirrhosis. Therefore, we aimed to investigate whether serum chloride levels were associated with mortality of critically ill cirrhotic patients.

\section{Methods}

\section{Data source}

All data in this study were extracted from the Multiparameter Intelligent Monitoring in Intensive Care (MIMIC) III database version 1.4 [13]. MIMIC-III is an openly available database developed by the computational physiology laboratory of Massachusetts Institute of Technology. The database contains de-identified clinical data for over 50,000 adult intensive care unit (ICU) stays at Beth Israel Deaconess Medical Center in Boston, MA, from 2001 to 2012. The institutional review boards of the Massachusetts Institute of Technology and Beth Israel Deaconess Medical Center approved the establishment and use of the database.

\section{Study population and variable extraction}

The primary study population consists of adult (age $\geq 18$ years) ICU patients with cirrhosis. We defined hypochloremia as a serum chloride level less than $99 \mathrm{mEq} / \mathrm{L}$. We defined hyponatremia as a serum sodium level less than $135 \mathrm{mEq} / \mathrm{L}$. We excluded patients with: (i) liver transplantation, (ii) chronic renal failure which was defined by the Elixhauser comorbidity index, and (iii) initial chloride measurements completed more than $24 \mathrm{~h}$ after ICU admission. For patients who were admitted to the ICU more than once, only the first ICU stay was considered in this study. Records containing baseline characteristics were extracted within the first $24 \mathrm{~h}$ after admission.

Baseline variables included patient demographics (eg, age, gender), etiology of cirrhosis, MELD score, Sequential Organ Failure Assessment (SOFA) score, and measures of organ support (eg, mechanical ventilation, vasopressors, renal replacement therapy). The MELD score was calculated according to the policy of the Organ Procurement and Transplant Network (OPTN) [14]. Laboratory data including serum chloride and sodium values, international normalized ratio, bilirubin, creatinine, hemoglobin, platelet count, and white blood cell count were measured during the first $24 \mathrm{~h}$ in the ICU. If a variable was recorded several times in the first $24 \mathrm{~h}$, we used the first value to analyze. A 1.5 -fold increase in the admission serum creatinine level relative to the baseline was considered to reflect acute kidney injury (AKI) according to the Kidney Disease Improving Global Outcome criteria [15]. The minimum value of serum creatinine available within the 7 days before admission was used as the baseline serum creatinine level. For patients without previous serum creatinine, it was estimated using the following formula: serum creatinine level $=0.74-0.2$ (if female) +0.08 (if black) $+0.003 \times$ age (in years) [16] The primary outcome of interest was ICU mortality, defined as death before ICU discharge.

\section{Statistical analysis}

Categorical data were shown as frequency (percent), while continuous ones as mean (standard deviation [SD]) or median (interquartile range [IQR]). We did comparisons between groups by the $\chi^{2}$ test or Fisher's exact test for categorical data and the Student $t$ test or the Wilcoxon rank-sum test for continuous ones. A multivariable logistic model was constructed to evaluate the association between the occurrence of hypochloremia and mortality. Covariables used in the multivariable logistic model were age, gender, ethnicity, MELD score, SOFA score, Elixhauser comorbidity index, mechanical ventilation, vasopressors, renal replacement therapy, AKI, hemoglobin, platelet, white blood cell, and sodium. These covariables were selected based on clinical relevance for risk of death (age, gender) or statistical criteria (univariable $p<0.05$ for inclusion in the analysis). International normalized ratio, bilirubin and creatinine are included in the MELD score and were therefore not separately included in the multivariable logistic model. The results were expressed as odds ratios (ORs) with $95 \%$ confidence intervals (CIs). The authors expected that the effect of hypochloremia on mortality would vary depending on patient characteristics. Accordingly, this potential heterogeneity was assessed by subgroup analyses stratified by age, gender, ethnicity, ICU type, etiology of cirrhosis, Elixhauser comorbidity index, MELD score, SOFA score, international normalized ratio, bilirubin, creatinine, hemoglobin, platelet, white blood cell, vasopressors, and mechanical ventilation. Cut-off values of continuous data for subgroup analyses were based on the median value of the whole study population. The Lowess smoothing technique was further used to explore the relationship 
between chloride and mortality [17]. The area under the receiver operating characteristic curves (AUC) was used to assess the performance of chloride and sodium for predicting mortality. Bonferroni correction was used for multiple comparisons, if needed. A two-tailed test was performed, and $p<0.05$ was considered statistically significant. All statistical analyses were performed using STATA V.16.0.

\section{Results}

\section{Baseline characteristics}

Data on 1216 patients were included in this study (Fig. 1). The baseline characteristics of the cohort are listed in Table 1 . The overall median age was 56 years, $67.5 \%$ were men, $69.5 \%$ were white, and $48.8 \%$ were alcohol-related. The median Elixhauser comorbidity index was 19, the median MELD score was 18, and the median SOFA score was 7. Mechanical ventilation, vasopressors, and renal replacement therapy were required for $46.7 \%, 25.6 \%$, and $4.1 \%$ of patients, respectively.

At baseline 199 patients (16.4\%) showed serum chloride levels $<99 \mathrm{mEq} / \mathrm{L}$. As shown in Table 1 , patients with hypochloremia, when compared to those without, had lower serum sodium levels, and higher bilirubin, creatinine, international normalized ratio, and white blood cell count. The hypochloremic group had higher Elixhauser comorbidity indices, MELD scores, and SOFA scores calculated at ICU admission.

\section{Hypochloremia and ICU mortality}

The overall ICU mortality rate was $18.8 \%$. Patients with hypochloremia were noted to have a higher ICU mortality rate of $34.2 \%$, compared with $15.8 \%$ in the nonhypochloremic group $(p<0.001)$. Univariable analysis showed that admission chloride levels expressed as continuous variables were inversely associated with ICU mortality (OR 0.96; 95\% CI 0.94-0.97; p <0.001) (Table 2). After multivariable risk adjustment for age, gender, ethnicity, MELD score, SOFA score, Elixhauser

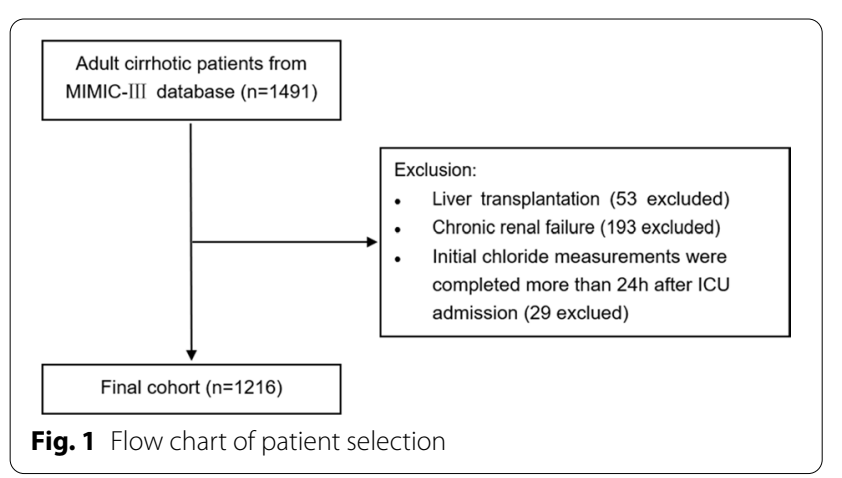

comorbidity index, mechanical ventilation, vasopressors, renal replacement therapy, AKI, hemoglobin, platelet, white blood cell, and sodium, admission chloride levels remained independently associated with ICU mortality. Every unit decrease in chloride level was associated with a $6 \%$ relative increment in ICU mortality risk (OR 0.94; 95\% CI 0.91-0.98; $p=0.002$ ) (Table 2). In the subgroup analyses, the association between admission chloride levels and the risk of ICU mortality remained relatively consistent across dichotomized subgroups of: medical ICU (MICU) or non-MICU patients, alcoholic or nonalcoholic cirrhosis, Elixhauser comorbidity index less than or greater than or equal to 19, SOFA score less than or greater than or equal to 7 , bilirubin less than or greater than or equal to $3 \mathrm{mg} / \mathrm{dL}$, white blood cell count less than or greater than or equal to $8.7 \times 10^{9} / \mathrm{L}$, and use of mechanical ventilation (Fig. 2).

\section{Chloride and sodium serum levels}

Admission chloride and sodium levels were strongly correlated each other $(\mathrm{r}=0.771 ; p<0.001)$. ICU mortality rates of patients stratified by both serum chloride and sodium are shown in Fig. 3, which illustrates different ICU mortality rates among groups $(p<0.001)$. Pairwise comparisons between groups revealed significant differences between patients with hypochloremia combined with hyponatremia $(36.6 \%)$ vs. patients with neither hypochloremia nor hyponatremia $(16.1 \%)(p<0.001)$ and between patients with hypochloremia combined with hyponatremia $(36.6 \%)$ vs. patients with hyponatremia alone $(14.6 \%)(p<0.001)$ (Fig. 3$)$.

At univariable analysis, like admission chloride levels, admission sodium levels were inversely associated with ICU mortality (OR 0.97; 95\% CI 0.95-0.99; $p=0.010$ ). However, admission sodium levels were no longer negatively associated with mortality after multivariable adjustment (OR 1.03; 95\% CI 0.99-1.08; $p=0.119$ ) (Table 2). The AUC for predicting ICU mortality of admission chloride levels (AUC, 0.600; 95\% CI 0.556-0.643) was statistically higher than that of admission sodium levels (AUC, 0.544; 95\% CI 0.499-0.590) $(p<0.001)$ (Fig. 4). Adding admission chloride levels to MELD score numerically improved the AUC from 0.770 to 0.774 for predicting ICU mortality, but this difference was not statistically significant $(p=0.066)$.

\section{ICU mortality according to three chloride groups}

In addition to the above analyses based on 2 groups (hypochloremia vs. non-hypochloremia), patients were also divided into 3 groups: hypochloremia $(<99 \mathrm{mEq} / \mathrm{L}$, $\mathrm{n}=199)$, normochloremia $(\geq 99$ and $<110 \mathrm{mEq} / \mathrm{L}$, $\mathrm{n}=730)$, and hyperchloremia $(\geq 110 \mathrm{mEq} / \mathrm{L}, \mathrm{n}=287)$. 
Table 1 Baseline characteristics of study participants

\begin{tabular}{|c|c|c|c|c|}
\hline & Total patients $(n=1216)$ & $\begin{array}{l}\text { Chloride }<99 \mathrm{mEq} / \mathrm{L} \\
(\mathrm{n}=199)\end{array}$ & $\begin{array}{l}\text { Chloride } \geq 99 \mathrm{mEq} / \mathrm{L} \\
(\mathrm{n}=1017)\end{array}$ & $p$ value \\
\hline Age, years & $56(49-65)$ & $54(49-63)$ & $57(50-65)$ & 0.056 \\
\hline Male, n (\%) & $821(67.5)$ & $129(64.8)$ & $692(68.0)$ & 0.375 \\
\hline Ethnicity, n (\%) & & & & 0.087 \\
\hline White & $845(69.5)$ & $150(75.4)$ & $695(68.3)$ & \\
\hline Black & $88(7.2)$ & $8(4.0)$ & $80(7.9)$ & \\
\hline Hispanic & $69(5.7)$ & $7(3.5)$ & $62(6.1)$ & \\
\hline Other & $214(17.6)$ & $34(17.1)$ & $180(17.7)$ & \\
\hline ICU type, n (\%) & & & & 0.157 \\
\hline MICU & $741(60.9)$ & $130(65.3)$ & $611(60.1)$ & \\
\hline SICU/TSICU & $362(29.8)$ & $48(24.1)$ & $314(30.9)$ & \\
\hline CCU/CSRU & $113(9.3)$ & $21(10.6)$ & $92(9.1)$ & \\
\hline Etiology of cirrhosis, n (\%) & & & & 0.165 \\
\hline Alcoholic & $593(48.8)$ & $106(53.3)$ & $487(47.9)$ & \\
\hline Non-alcoholic & $623(51.2)$ & $93(46.7)$ & $530(52.1)$ & \\
\hline Elixhauser comorbidity index & $19(12-30)$ & $25(17-32)$ & $19(11-29)$ & $<0.001$ \\
\hline MELD score & $18(13-27)$ & $26(18-38)$ & $17(13-25)$ & $<0.001$ \\
\hline SOFA score & $7(4-10)$ & $8(6-12)$ & $6(4-9)$ & $<0.001$ \\
\hline Mechanical ventilation, n (\%) & $568(46.7)$ & $81(40.7)$ & $487(47.9)$ & 0.063 \\
\hline Vasopressors, n (\%) & $311(25.6)$ & $62(31.2)$ & $249(24.5)$ & 0.049 \\
\hline Renal replacement therapy, n (\%) & $50(4.1)$ & $17(8.5)$ & $33(3.2)$ & 0.001 \\
\hline Acute kidney injury, n (\%) & $240(19.7)$ & $79(39.7)$ & $161(15.8)$ & $<0.001$ \\
\hline \multicolumn{5}{|l|}{ Blood tests results } \\
\hline Chloride, mEq/L & $105(101-109)$ & $95(92-97)$ & $107(103-110)$ & $<0.001$ \\
\hline Sodium, mEq/L & $137(134-141)$ & $129(125-133)$ & $139(136-141)$ & $<0.001$ \\
\hline Bilirubin, mg/dL & $3.0(1.5-7.1)$ & $6.2(2.1-17.0)$ & $2.8(1.4-5.6)$ & $<0.001$ \\
\hline Creatinine, $\mathrm{mg} / \mathrm{dL}$ & $1.0(0.7-1.5)$ & $1.4(0.9-2.7)$ & $0.9(0.7-1.4)$ & $<0.001$ \\
\hline International normalized ratio & $1.6(1.4-2.0)$ & $1.9(1.5-2.7)$ & $1.6(1.3-1.9)$ & $<0.001$ \\
\hline Hemoglobin, g/dL & $10.2(9.0-11.5)$ & $10.2(8.9-11.7)$ & $10.2(9.0-11.5)$ & 0.769 \\
\hline Platelet, $10^{9} / \mathrm{L}$ & $106(71-157)$ & $106(71-156)$ & $106(71-157)$ & 0.986 \\
\hline White blood cell, $10^{9} / \mathrm{L}$ & $8.7(5.5-13.6)$ & $9.9(7.1-15.8)$ & $8.4(5.3-13.0)$ & $<0.001$ \\
\hline \multicolumn{5}{|l|}{ Outcome } \\
\hline ICU mortality, n (\%) & $229(18.8)$ & $68(34.2)$ & $161(15.8)$ & $<0.001$ \\
\hline
\end{tabular}

CCU, coronary care unit; CSRU, cardiac surgery care unit; ICU, intensive care unit; MELD, Model for End-stage Liver Disease; MICU, medical intensive care unit; SICU, surgical intensive care unit; SOFA, Sequential Organ Failure Assessment; TSICU, traumatic surgical intensive care unit

Patients with hypochloremia had a higher ICU mortality rate of $34.2 \%$, compared with $15.9 \%$ in the normonatremic group $(p<0.001)$. However, the ICU mortality rate was similar between patients with hyperchloremia (15.7\%) and with normochloremia (15.9\%). Figure 5 shows the relationship between admission chloride levels and ICU mortality determined using the Lowess smoothing technique. The ICU mortality rate was numerically higher in patients with severe hyperchloremia $(\geq 115 \mathrm{mEq} / \mathrm{L})$ than in patients with normonatremia, but this difference was not statistically significant $(21.3 \%$ vs. $15.9 \%, p=0.219)$.

\section{Discussion}

In this cohort study, we report several key observations regarding the prognostic importance of serum chloride in critically ill patients with cirrhosis. First, serum chloride levels were independently and inversely associated with ICU mortality, both univariately and multivariately. This result remained relatively consistent across different subgroups. Second, the ICU mortality rate was significantly higher in patients with hypochloremia, irrespective of their admission sodium levels. Third, serum sodium levels were no longer negatively associated with mortality at multivariable analysis. These findings highlight that while the link between hyponatremia and mortality has been 
Table 2 Logistic regression analysis for ICU mortality

\begin{tabular}{|c|c|c|c|c|}
\hline & Univariable & $p$ value & Multivariable & $p$ value \\
\hline Chloride, per $1 \mathrm{mEq} / \mathrm{L}$ increase & $0.96(0.94-0.97)$ & $<0.001$ & $0.94(0.91-0.98)$ & 0.002 \\
\hline Sodium, per $1 \mathrm{mEq} / \mathrm{L}$ increase & $0.97(0.95-0.99)$ & 0.010 & $1.03(0.99-1.08)$ & 0.119 \\
\hline Age per year increase & $1.01(1.00-1.02)$ & 0.098 & $1.02(1.01-1.04)$ & 0.002 \\
\hline \multicolumn{5}{|l|}{ Gender } \\
\hline Female & 1 [Reference] & & 1 [Reference] & \\
\hline Male & $0.83(0.62-1.13)$ & 0.234 & $0.86(0.60-1.24)$ & 0.422 \\
\hline \multicolumn{5}{|l|}{ Ethnicity } \\
\hline Other & 1 [Reference] & & 1 [Reference] & \\
\hline White & $0.52(0.37-0.73)$ & $<0.001$ & $0.73(0.47-1.13)$ & 0.155 \\
\hline Black & $0.64(0.36-1.17)$ & 0.150 & $1.03(0.49-2.19)$ & 0.935 \\
\hline Hispanic & $0.20(0.08-0.51)$ & 0.001 & $0.40(0.13-1.18)$ & 0.098 \\
\hline \multicolumn{5}{|l|}{ ICU type } \\
\hline $\mathrm{MICU}$ & 1 [Reference] & & & \\
\hline SICU/TSICU & $0.89(0.64-1.23)$ & 0.481 & & \\
\hline CCU/CSRU & $1.14(0.70-1.85)$ & 0.604 & & \\
\hline \multicolumn{5}{|l|}{ Etiology of cirrhosis } \\
\hline Non-alcoholic & 1 [Reference] & & & \\
\hline Alcoholic & $1.28(0.96-1.70)$ & 0.097 & & \\
\hline Elixhauser comorbidity index, per point increase & $1.03(1.02-1.04)$ & $<0.001$ & $1.01(0.99-1.02)$ & 0.243 \\
\hline MELD score, per point increase & $1.10(1.09-1.12)$ & $<0.001$ & $1.04(1.01-1.06)$ & 0.007 \\
\hline SOFA score, per point increase & $1.39(1.32-1.45)$ & $<0.001$ & $1.20(1.12-1.30)$ & $<0.001$ \\
\hline \multicolumn{5}{|l|}{ Mechanical ventilation } \\
\hline No & 1 [Reference] & & 1 [Reference] & \\
\hline Yes & $3.29(2.4-4.48)$ & $<0.001$ & $2.61(1.74-3.90)$ & $<0.001$ \\
\hline \multicolumn{5}{|l|}{ Vasopressors } \\
\hline No & 1 [Reference] & & 1 [Reference] & \\
\hline Yes & $4.81(3.55-6.53)$ & $<0.001$ & $1.42(0.93-2.17)$ & 0.103 \\
\hline \multicolumn{5}{|l|}{ Renal replacement therapy } \\
\hline No & 1 [Reference] & & 1 [Reference] & \\
\hline Yes & $5.60(3.15-9.97)$ & $<0.001$ & $0.63(0.30-1.32)$ & 0.221 \\
\hline \multicolumn{5}{|l|}{ Acute kidney injury } \\
\hline No & 1 [Reference] & & 1 [Reference] & \\
\hline Yes & $3.81(2.77-5.23)$ & $<0.001$ & $1.56(1.03-2.37)$ & 0.037 \\
\hline Hemoglobin, per $1 \mathrm{~g} / \mathrm{dL}$ increase & $0.90(0.83-0.97)$ & 0.005 & $0.94(0.86-1.03)$ & 0.189 \\
\hline Platelet, per $1 \times 10^{9} / \mathrm{L}$ increase & $1.00(1.00-1.00)$ & 0.004 & $1.00(1.00-1.00)$ & 0.473 \\
\hline White blood cell, per $1 \times 10^{9} / \mathrm{L}$ increase & $1.05(1.03-1.07)$ & $<0.001$ & $1.04(1.01-1.06)$ & 0.008 \\
\hline
\end{tabular}

CCU, coronary care unit; CSRU, cardiac surgery care unit; ICU, intensive care unit; MELD, Model for End-stage Liver Disease; MICU, medical intensive care unit; SICU, surgical intensive care unit; SOFA, Sequential Organ Failure Assessment; TSICU, traumatic surgical intensive care unit

focused on to date, we should now recognize the prognostic value of serum chloride in patients with cirrhosis.

These findings uncover two possible scenarios. In a first one, the onset of hypochloremia is the consequence of the progressive course of cirrhosis. In this case, hypochloremia is an important biomarker of cirrhosis progression. However, it is also possible that hypochloremia could mediate the worse prognosis of cirrhotic patients. In this second possible scenario, hypochloremia represents an exacerbation factor in cirrhotic patients.
The observational nature of this study did not allow us to determine this answer. More work is needed.

To date, few studies have evaluated the prognostic significance of serum chloride in patients with cirrhosis $[18,19]$. In decompensated cirrhotic patients in the ICU ( $n=389)$, Sumarsono et al. [18] found that serum chloride levels were independently and inversely associated with 180-day mortality. In cirrhotic patients with acute upper gastrointestinal bleeding $(n=683)$, Ning et al. [19] found that the in-hospital mortality rate 
a

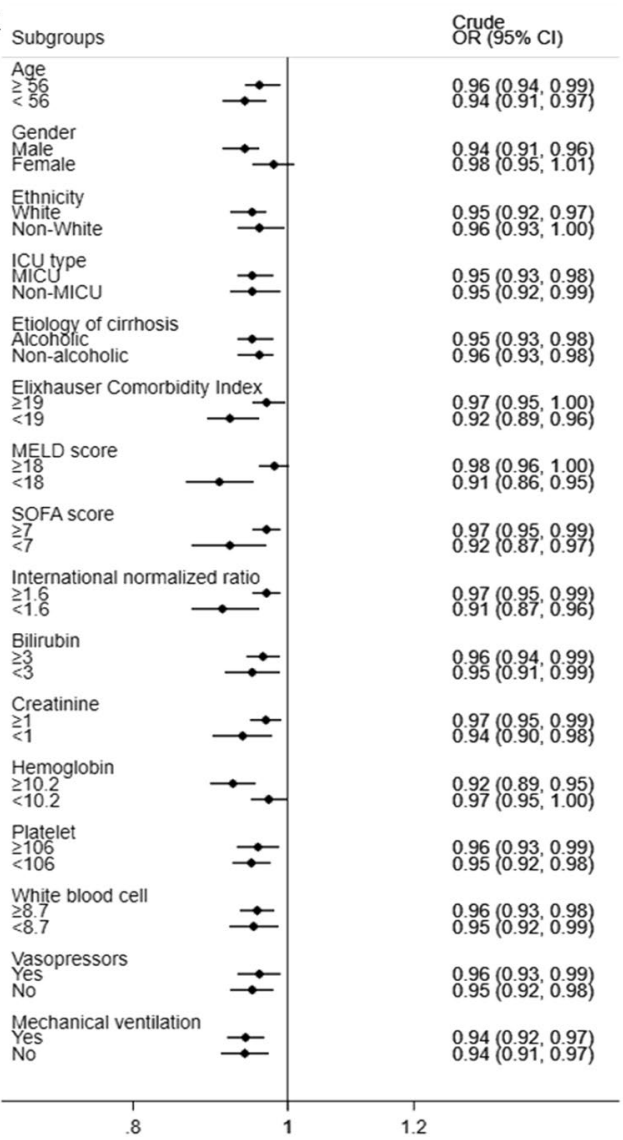

b

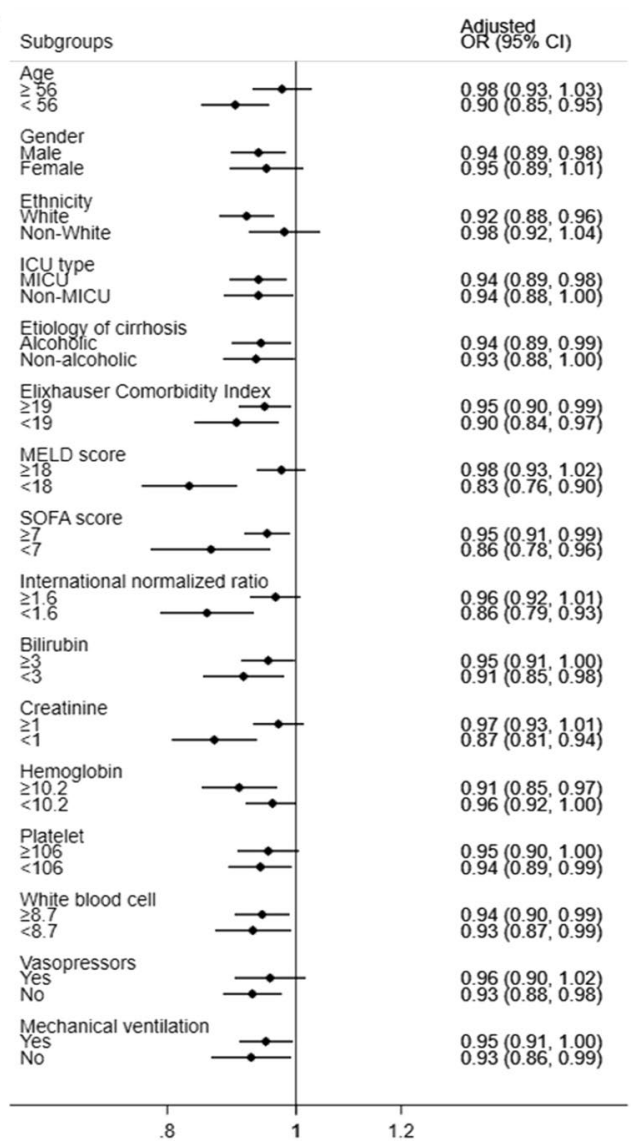

Fig. 2 Subgroup analyses of the association between chloride and ICU mortality

was $9.8 \%$ in hypochloremic group, $2.5 \%$ in normochloremic group, and $8.5 \%$ in hyperchloremic group. They also found that higher serum chloride levels were positively associated with increased in-hospital mortality of cirrhotic patients with acute upper gastrointestinal bleeding.

Our current study with 1216 enrolled patients represents the largest collective that has been analyzed for the prognostic relevance of serum chloride in cirrhotic patients to date. Our results support the findings of Sumarsono et al. [18]. However, our results were not identical to the findings of Ning et al. [19]. Both studies (ours and that of Ning et al. [19]) found that cirrhotic patients with hypochloremia had a higher mortality rate. Ning et al. [19] also found that hyperchloremia was associated with increased mortality rate, which was not identified in our study. Differences in results between the two studies might be due to different populations. In particular, we focused on ICU cirrhotic patients, whereas Ning et al. [19] focused on cirrhotic patients with acute upper gastrointestinal bleeding. Acute bleeding events, as we know, can lead to pachyemia and high blood viscosity, which may cause the electrolyte concentrations to be increased [19].

Recently, some researchers have changed their focus from sodium to its often overlooked counter ion in salt, the chloride [20]. Growing evidence have shown that hypochloremia is associated with a higher risk of mortality in patients with acute or chronic heart failure, chronic kidney disease, and pulmonary hypertension [7-12, 21]. It is noteworthy that multiple studies have shown that serum chloride had better prognostic predictability than serum sodium $[9,10,12]$. In our study, lower chloride levels were associated with higher mortality after multivariable adjustment for known prognostic factors including serum sodium. More interestingly, however, lower sodium levels were no longer associated with higher mortality when serum chloride was added to the multivariable model. Importantly, our study showed that serum chloride had a higher predictive ability for mortality when compared to serum sodium. It is therefore that serum chloride may provide more robust prognostic information than serum sodium in patients with cirrhosis. Our findings highlight the need to focus on better 


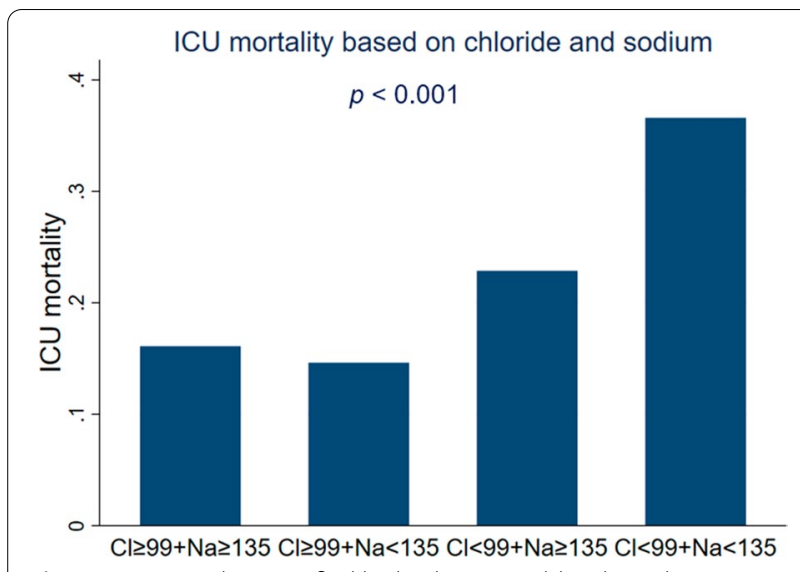

Fig. 3 ICU mortality stratified by both serum chloride and serum sodium levels. Patients were divided into groups with neither hypochloremia nor hyponatremia, with hyponatremia alone, with hypochloremia alone, and with hypochloremia combined with hyponatremia, which were significantly different $(p<0.001)$. Pairwise comparisons with adjustment for multiple comparisons demonstrated significant differences between patients with hypochloremia combined with hyponatremia (36.6\%) vs. patients with neither hypochloremia nor hyponatremia $(16.1 \%)(p<0.001)$ and between patients with hypochloremia combined with hyponatremia $(36.6 \%)$ vs. patients with hyponatremia alone $(14.6 \%)(p<0.001)$

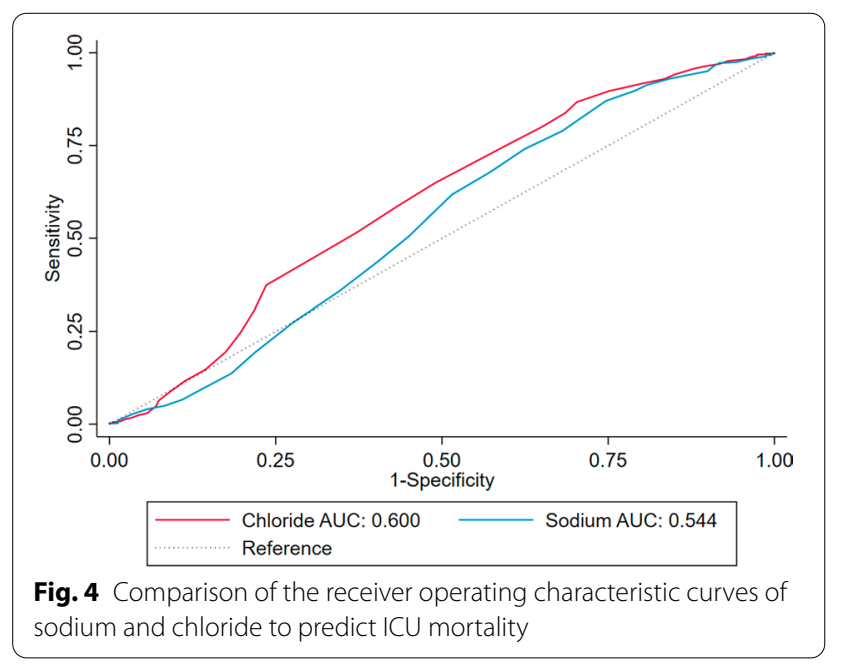

understanding of chloride homeostasis in patients with cirrhosis.

Whether or not a causal association exists between hypochloremia and increased mortality risk in patients with cirrhosis needs further investigation, however there are possible pathophysiological mechanisms, which might link this association. The progressive course of cirrhosis with portal hypertension and splanchnic vasodilatation leads to the development of effective arterial hypovolemia and activation of endogenous

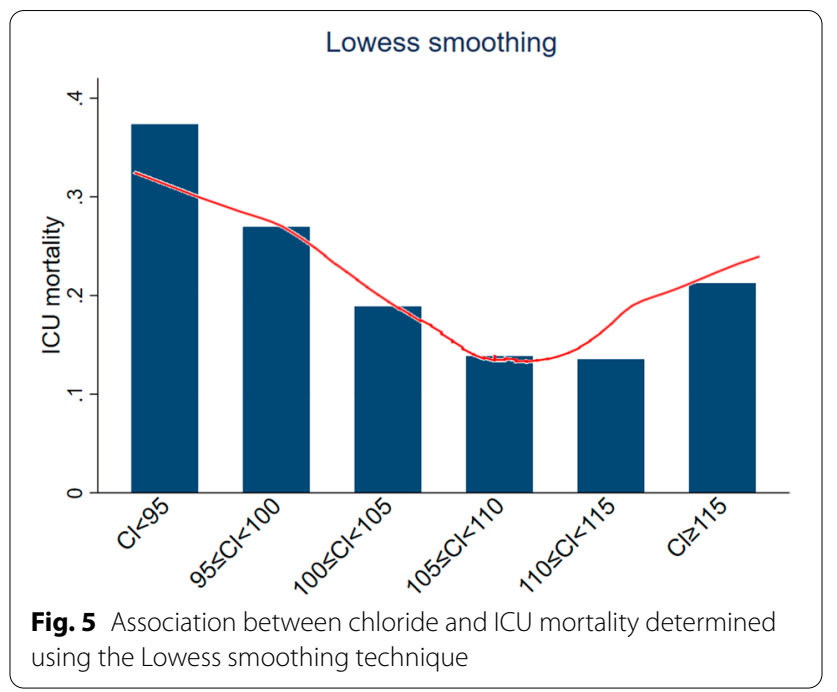

vasoconstrictor systems causing various complications, including cirrhotic cardiomyopathy, hepatorenal syndrome, and hepatopulmonary syndrome [22, 23]. Since serum chloride has been recognized to play a critical role in modulation of renin secretion, renal salt sensing, tubuloglomerular feedback, and regulation of sodium transporter [21, 24, 25], it is mechanistically conceivable that hypochloremia could promote greater cirrhosis-related complications and risk for death. Future prospective studies should examine the influence of hypochloremia on the development of cirrhosis-related complications.

In advanced cirrhosis, maladaptive neurohormonal activation (increase in arginine vasopressin and reninangiotensin-aldosterone system) leads to increased free water retention, which may result in reduced plasma concentrations of chloride [23]. Perturbations in chloride homeostasis may be further exacerbated by frequent fluid challenges or diuretics use. Thus, we expected that fluids or diuretics given prior to admission would be a driver of admission hypochloremia. Although the impact of fluids or diuretics was not examined in our study, we think that we should pay more attention to the cirrhotic patients treated with fluids or diuretics.

The major strength of our study is the large number of patients with cirrhosis; however, there are also several limitations to our study. First, the study was limited by its retrospective nature. Second, since the study was using a relatively old database with data from 2001 to 2012 , the data may not accurately reflect the current situation. Third, we evaluated chloride concentration only at one point of time in cirrhotic patients. Therefore, we were unable to assess the prognostic role of serum chloride changes in cirrhotic patients. Fourth, although we did our best to use a multivariable model to control 
bias, there remain the possibility of confounding variables that were not examined in our multivariable model. Fifth, we were unable to calculate the ChildPugh score, as some of the necessary clinical data were not available in the database. Other scoring systems, such as albumin-bilirubin score [26] and chronic liver failure-sequential organ failure (CLIF-SOFA) score [27], have been recently proposed for prognostic assessment of cirrhosis. Although albumin-bilirubin score is simple, albumin was not measured in 40 percent of the study population during the first $24 \mathrm{~h}$ in the ICU. The CLIF-SOFA components include: $\mathrm{SpO}_{2} / \mathrm{FiO}_{2}$ or $\mathrm{PaO}_{2} /$ $\mathrm{FiO}_{2}$, hypotension (mean arterial pressure, vasopressor use), international normalized ratio, hepatic encephalopathy grade, and serum creatinine [27]. We were unable to reliably determine hepatic encephalopathy grade in the database. Therefore, we did not assess these prognostic scores in this study. Despite these limitations, this study provides new insight into the prognostic role of chloride in cirrhotic patients. Future studies are required to assess the performance of a composite score containing serum chloride (such as MELD-Cl or MELD-Na-Cl) and to determine whether therapeutic maintenance of chloride homeostasis can improve survival in cirrhotic patients [18].

\section{Conclusions}

In conclusion, this study shows that serum chloride levels are independently and inversely associated with ICU mortality in critically ill cirrhotic patients. This finding highlights the clinical significance of chloride, a routinely measured electrolyte, in prognostication for critically ill cirrhotic patients.

\section{Abbreviations}

$\mathrm{Cl}$ : Confidence interval; ICU: Intensive care unit; IQR: Interquartile ranges: MELD: Model for End-stage Liver Disease; MIMIC: Medical Information Mart for Intensive Care; OR: Odds ratio; SD: Standard deviation; SOFA: Sequential organ failure assessment.

\section{Acknowledgements}

None.

\section{Authors' contributions}

YJ designed the study, extracted the data, performed the statistical analyses, and drafted the manuscript. LL critically reviewed and approved the final version of the manuscript for submission. All authors read and approved the final manuscript.

\section{Funding}

None.

\section{Availability of data and materials}

The datasets presented in the current study are available in the MIMIC III database (https://physionet.org/works/MIMICIIIClinicalDatabase/files/).

\section{Declarations}

\section{Ethics approval and consent to participate}

The establishment of this database was approved by the Massachusetts Institute of Technology (Cambridge, MA) and Beth Israel Deaconess Medical Center (Boston, MA) and consent was obtained for the original data collection. Therefore, the ethical approval statement and the need for informed consent were waived for this manuscript.

\section{Consent for publication}

Not applicable.

\section{Competing interests}

The authors declare that they have no competing interests.

Received: 2 December 2020 Accepted: 27 April 2021

Published online: 01 May 2021

\section{References}

1. Musso CG, Juarez R, Glassock RJ. Water, electrolyte, acid-base, and trace elements alterations in cirrhotic patients. Int Urol Nephrol. 2018;50(1):81-9.

2. Ginés P, Berl T, Bernardi M, Bichet DG, Hamon G, Jiménez W, Liard JF, Martin PY, Schrier RW. Hyponatremia in cirrhosis: from pathogenesis to treatment. Hepatology. 1998;28(3):851-64.

3. John S, Thuluvath PJ. Hyponatremia in cirrhosis: pathophysiology and management. World J Gastroenterol. 2015;21(11):3197-205.

4. Kim WR, Biggins SW, Kremers WK, Wiesner RH, Kamath PS, Benson JT, Edwards E, Therneau TM. Hyponatremia and mortality among patients on the liver-transplant waiting list. N Engl J Med. 2008;359(10):1018-26.

5. Yunos NM, Bellomo R, Story D, Kellum J. Bench-to-bedside review: Chloride in critical illness. Crit Care. 2010;14(4):226.

6. Berend K, van Hulsteijn LH, Gans RO. Chloride: the queen of electrolytes? Eur J Intern Med. 2012;23(3):203-11.

7. Zhang Y, Peng R, Li X, Yu J, Chen X, Zhou Z. Serum chloride as a novel marker for adding prognostic information of mortality in chronic heart failure. Clin Chim Acta. 2018:483:112-8.

8. Cuthbert JJ, Pellicori P, Rigby A, Pan D, Kazmi S, Shah P, Clark AL. Low serum chloride in patients with chronic heart failure: clinical associations and prognostic significance. Eur J Heart Fail. 2018;20(10):1426-35.

9. Grodin JL, Simon J, Hachamovitch R, Wu Y, Jackson G, Halkar M, Starling RC, Testani JM, Tang WH. Prognostic role of serum chloride levels in acute decompensated heart failure. J Am Coll Cardiol. 2015;66(6):659-66.

10. Kubota K, Sakaguchi Y, Hamano T, Oka T, Yamaguchi S, Shimada K, Matsumoto A, Hashimoto N, Mori D, Matsui I, et al. Prognostic value of hypochloremia versus hyponatremia among patients with chronic kidney disease-a retrospective cohort study. Nephrol Dial Transplant. 2020:35(6):987-94.

11. Mandai S, Kanda E, limori S, Naito S, Noda Y, Kikuchi H, Akazawa M, Oi K, Toda T, Sohara E, et al. Association of serum chloride level with mortality and cardiovascular events in chronic kidney disease: the CKD-ROUTE study. Clin Exp Nephrol. 2017;21(1):104-11.

12. Testani JM, Hanberg JS, Arroyo JP, Brisco MA, Ter Maaten JM, Wilson FP, Bellumkonda L, Jacoby D, Tang WH, Parikh CR. Hypochloraemia is strongly and independently associated with mortality in patients with chronic heart failure. Eur J Heart Fail. 2016;18(6):660-8.

13. Johnson AE, Pollard TJ, Shen L, Lehman LW, Feng M, Ghassemi M, Moody B, Szolovits P, Celi LA, Mark RG. MIMIC-III, a freely accessible critical care database. Sci Data. 2016:3:160035.

14. Liver and Intestinal Organ Transplantation Committee (2015) Clerical changes for implementation of adding serum sodium to the MELD score. Organ Procurement and Transplantation Network (OPTN), Richmond, Virgina. Available via https://optn.transplant.hrsa.gov/media/1575/polic ynotice_20151101.pdf. Accessed 30 Dec 2020.

15. Kellum JA, Lameire N. Diagnosis, evaluation, and management of acute kidney injury: a KDIGO summary (Part 1). Crit Care. 2013;17(1):204.

16. Závada J, Hoste E, Cartin-Ceba R, Calzavacca P, Gajic O, Clermont G, Bellomo R, Kellum JA. A comparison of three methods to estimate 
baseline creatinine for RIFLE classification. Nephrol Dial Transplant. 2010;25(12):3911-8.

17. Brook K, Camargo CA, Christopher KB, Quraishi SA. Admission vitamin $D$ status is associated with discharge destination in critically ill surgical patients. Ann Intensive Care. 2015;5(1):23.

18. Sumarsono A, Wang J, Xie L, Chiang GC, Tielleman T, Messiah SE, Singal AG, Mufti A, Chen C, Leveno M. Prognostic value of hypochloremia in critically III patients with decompensated cirrhosis. Crit Care Med. 2020;48(11):e1054-61.

19. Ning Z, Qi X, Hou F, Zhao J, Peng Y, Li H, Li J, Deng H, Zhang X, Guo X. Serum sodium, potassium, calcium, and chlorine for predicting the in-hospital mortality in cirrhotic patients with acute upper gastrointestinal bleeding: a retrospective observational study. Int J Clin Exp Med. 2016;9(5):8264-71.

20. Kazory A, Ronco C. Emergence of chloride as an overlooked cardiorenal connector in heart failure. Blood Purif. 2020;49(1-2):219-21.

21. Naal T, Abuhalimeh B, Khirfan G, Dweik RA, Tang WHW, Tonelli AR. Serum chloride levels track with survival in patients with pulmonary arterial hypertension. Chest. 2018;154(3):541-9.

22. Wiese S, Hove JD, Bendtsen F, Møller S. Cirrhotic cardiomyopathy: pathogenesis and clinical relevance. Nat Rev Gastroenterol Hepatol. 2014;11(3):177-86.
23. Simonetto DA, Gines P, Kamath PS. Hepatorenal syndrome: pathophysiology, diagnosis, and management. BMJ. 2020;370:m2687.

24. Ponce-Coria J, San-Cristobal P, Kahle KT, Vazquez N, Pacheco-Alvarez D, de Los HP, Juárez P, Muñoz E, Michel G, Bobadilla NA, et al. Regulation of NKCC2 by a chloride-sensing mechanism involving the WNK3 and SPAK kinases. Proc Natl Acad Sci U S A. 2008;105(24):8458-63.

25. Piala AT, Moon TM, Akella R, He H, Cobb MH, Goldsmith EJ. Chloride sensing by WNK1 involves inhibition of autophosphorylation. Sci Signal. 2014;7(324):ra41.

26. Shao L, Han B, An S, Ma J, Guo X, Romeiro FG, Mancuso A, Qi X. Albuminto-bilirubin score for assessing the in-hospital death in cirrhosis. Transl Gastroenterol Hepatol. 2017;2:88.

27. Moreau R, Jalan R, Gines P, Pavesi M, Angeli P, Cordoba J, Durand F, Gustot T, Saliba F, Domenicali M et al. Acute-on-chronic liver failure is a distinct syndrome that develops in patients with acute decompensation of cirrhosis. Gastroenterology. 2013; 144(7):1426-1437, 1437.e1421-1429.

\section{Publisher's Note}

Springer Nature remains neutral with regard to jurisdictional claims in published maps and institutional affiliations.
Ready to submit your research? Choose BMC and benefit from:

- fast, convenient online submission

- thorough peer review by experienced researchers in your field

- rapid publication on acceptance

- support for research data, including large and complex data types

- gold Open Access which fosters wider collaboration and increased citations

- maximum visibility for your research: over $100 \mathrm{M}$ website views per year

At BMC, research is always in progress.

Learn more biomedcentral.com/submissions 